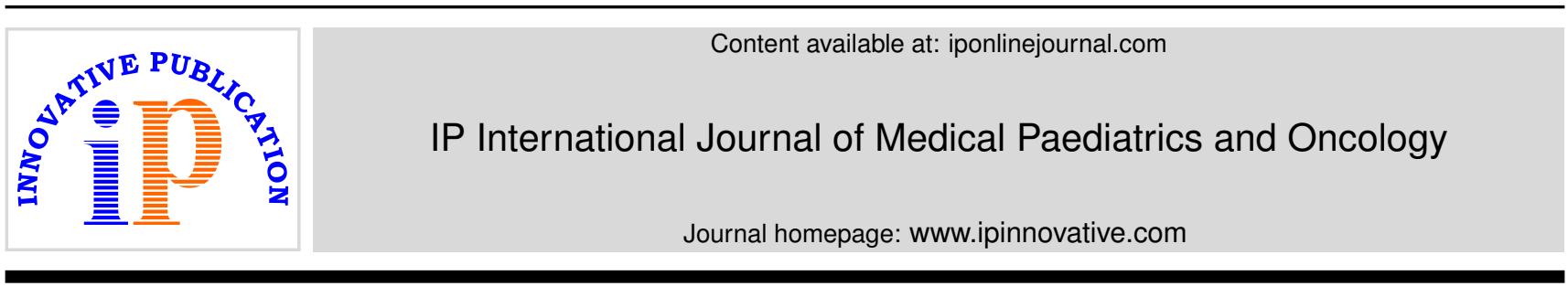

Original Research Article

\title{
Role of upper gastrointestinal endoscopy in children with iron deficiency anemia in western Rajasthan
}

\author{
Chandradeep Mastan ${ }^{1}$, Rakesh Jora ${ }^{1, *}$, Priyanka Karnani ${ }^{1}$ \\ ${ }^{1}$ Dept. of Pediatrics, S.N Medical College, Jodhpur, Rajasthan, India
}

\section{A R T I C L E I N F O}

\section{Article history:}

Received 20-04-2020

Accepted 01-05-2020

Available online 18-07-2020

\section{Keywords:}

Upper gastrointestinal endoscopy

Duodenal biopsy

Iron deficiency anemia

\begin{abstract}
A B S T R A C T
Background: Upper gastrointestinal (UGI) endoscopy reveals abnormal pathological findings in 55\% patients of iron deficiency anemia therefore gastrointestinal pathology should be ruled out iron deficiency anemia not responding to the treatment.

Aim: To determine the role of upper gastrointestinal endoscopy and find out the pathological changes which occur in children with iron deficiency anemia (IDA)

Materials and Methods: This cross-sectional study included 95 pediatric patients with iron deficiency anemia in the age group between 3 to 17 years who underwent routine upper gastrointestinal endoscopy. All potential bleeding lesions were identified and biopsy samples were taken from $2^{\text {nd }}$ part of duodenum for histopathological examinations.

Results: The mean age of cases was $7.3 \pm 3.3$ years. Endoscopy revealed abnormal finding in $63.1 \%$ patients. The gastrointestinal pathologies identified were celiac disease in 22 patients, nonspecific duodenitis in 11 patients, H.Pylori duodenitis in 8 patients, erosive duodenitis in 7 patients and giardiasis in 3 patients.

Conclusion: Upper gastrointestinal endoscopy has a definitive role in identifying the underlying cause of iron deficiency anemia in patients not responding to conventional therapy.

(C) 2020 Published by Innovative Publication. This is an open access article under the CC BY-NC license (https://creativecommons.org/licenses/by-nc/4.0/)
\end{abstract}

\section{Introduction:}

Iron deficiency is the most prevalent nutritional deficiency in the world, and probably the most important micronutrient deficiency in the developing countries. ${ }^{1}$ Reduced iron absorption and insidious blood loss of variable etiology from the gastrointestinal tract has been identified as the most frequent causes of Iron deficiency (ID) and Iron deficiency anemia (IDA) in older children and adolescents. The intensity of diagnostic efforts to identify underlying pathology depends on the likelihood of encountering such pathology. ${ }^{2}$

Gastrointestinal tract evaluation should be pursued in those who have severe anemia or remains refractory to iron treatment or have significant gastrointestinal symptoms, weight loss, positive fecal occult blood testing, or in

\footnotetext{
* Corresponding author.

E-mail address: jorarakesh@gmail.com (R. Jora).
}

those whose menstrual blood loss does not correlate with the severity of their IDA. Upper gastrointestinal (UGI) endoscopy reveals abnormal pathological findings in 55\% patients of iron deficiency anemia therefore gastrointestinal pathology should be ruled out before treating iron deficiency anemia. ${ }^{3-5}$

The role of routine endoscopic duodenal biopsies obtained for the evaluation of iron deficiency anemia, is being increasingly emphasized, but insufficiently applied in our region. So we have planned this study to assess the usefulness of upper gastro intestinal endoscopy \& duodenal biopsies in pediatric patients presenting with iron deficiency anemia who are not responding to conventional treatment.

\section{Material and Methods}

This study was a hospital based, cross-sectional observational study in which 95 children who presented to the 
Gastroenterology Unit of Department of Pediatrics, Dr. S.N. Medical College, Jodhpur over a period of one year in the age group of 3 to 17 years and diagnosed with IDA were enrolled. The study was approved by Ethics review committee of Dr S.N. Medical College, Jodhpur. Detailed history from parents or patients was recorded on predesigned proforma. Complete general physical and systemic examinations were done and anthropometry of each child was recorded.

Hematologic and biochemical parameters, such as complete hemogram, serum ferritin, serum iron (SI), and total serum iron binding capacity (SIBC) obtained at baseline. Transferrin saturation (TS) was calculated from these measurements. Venous blood samples for tissue transglutaminase $\operatorname{IgA}$ antibody (anti-tTG) were obtained from the patients prior to the endoscopic evaluation.

IDA was diagnosed as per WHO guidelines in those patients who had microcytic, hypochromic red cells on peripheral blood film examination with any one of the following -

1. Serum Iron $<60 \mathrm{ug} / \mathrm{dl}$

2. Serum Ferritin $<100 \mathrm{ng} / \mathrm{ml}$ (male or $<40 \mathrm{ng} / \mathrm{ml}$ (female

3. Total iron binding capacity $>400 \mathrm{ug} / \mathrm{dl}$

Patients with Hemoglobinopathie, anemia due to blood loss such as recent surgery, trauma, or overt gastrointestinal haemorrhage, chronic kidney disease \& who did not give consent for GI endoscopy were excluded from the study.

Written consent was obtained from the parents of all enrolled cases. All patients underwent upper gastrointestinal endoscopic study and two endoscopic biopsy specimens were taken one from the second part of duodenum and another from gastric antrum for H.Pylori. Biopsy specimens were routinely processed for conventional histological evaluation and evaluated by one expert histopathologist. SPSS 13.0 for Windows was used for statistical analysis.

\section{Results}

The mean age of study population was $7.3 \pm 3.3$ years and Male: Female ratio of 0.97:1. Biochemical characteristics of enrolled cases are shown Table 1.

Villous atrophy (34.7\%) was the commonest abnormal endoscopic finding which was mild in $8.4 \%$, moderate in $9.4 \%$ and severe in $16.8 \%$ patients followed by gastroesophageal junction hyperemia in $16.8 \%$ patients. $36.8 \%$ patients had normal endoscopic finding (Table 2). $42.1 \%$ patients had normal duodenal biopsy findings followed by changes of celiac disease in $36.84 \%$ out of which $12.6 \%$ cases had Marsh stage 2 followed by Marsh stage $3(11.6 \%)$ on histopathological examination. Nonspecific duodenitis was found in $11.6 \%$ cases while H. Pylori duodenitis in $9.5 \%$ cases (Table 3). Patient with villous atrophy, in which we had suspected celiac disease, had $100 \%$ serum TTG IgA positivity while patients with suspected celiac disease \& normal endoscopy had $40 \%$ serum anti-TTG positivity and this correlation was statistically significant. (chi Square value: 2.46 , p-value: $<0.05$ ). (Table 4). The most common comorbidity seen with iron deficiency anemia was celiac disease $(23.16 \%)$ followed by nonspecific duodenitis (11.58\%). $8.42 \%$ were diagnosed as $\mathrm{H}$. Pylori duodenitis. $41.05 \%$ cases had no comorbidity (Table 5).

$66.6 \%$ patients with severe anemia had villous atrophy and $43.7 \%$ had gastro esophageal hyperemia and this correlation was statistically significant. ( $\mathrm{p}$ value $<0.05$ ) Maximum patients with severe anemia (46.3\%) have abnormality in duodenal biopsy when compared to moderate $(34.7 \%)$ and mild anemia $(13.6 \%)$ and this correlation was statistically significant. ( $p$ value $<0.05$ ).

Table 1: Biochemical characteristics of study population

$\begin{array}{ll}\text { Mean haemoglobin } & 5.98 \pm 2.26 \mathrm{gm} / \mathrm{dl} \\ \text { Mean serum iron } & 25.74 \pm 13.80 \mu \mathrm{g} / \mathrm{dl} \\ \text { Mean serum ferritin } & 7.30 \pm 5.19 \mathrm{ng} / \mathrm{ml} \\ \text { Mean serum TIBC } & 483.67 \pm 118.35 \mu \mathrm{g} / \mathrm{dl} \\ \text { Mean transferrin saturation } & 8.45 \pm 4.12 \%\end{array}$

\section{Discussion}

It is estimated that $30 \%$ of the global population has iron deficiency anemia, and most of them live in developing countries. ${ }^{6}$ The role of routine endoscopic examination \& duodenal biopsies during the evaluation of iron deficiency anemia is being increasingly emphasized, but insufficiently applied in our region.

In our study, endoscopy revealed abnormal finding in $60(63.1 \%)$ patients. Our results were similar to study conducted by Huseyin Gulen et $\mathrm{al}^{7}$ in which they found $56.8 \%$ abnormal endoscopic findings in older children and adolescents with IDA. These abnormalities were found more in patients who had severe anemia on presentation compared to those with moderate or mild anemia and the results were statistically significant.

We also found additional diagnostic benefit of upper gastrointestinal endoscopy in $17.1 \%$ patients with iron deficiency anemia. Our results were similar to the study conducted by Can Gonen et $\mathrm{al}^{8}$ in which they found $5 \%$ additional diagnostic benefit of routine duodenal biopsy during upper gastrointestinal endoscopic examination in adult patients with iron deficiency anemia. There are different etiologies in children causing iron deficiency anemia and hence this practice should be included in the diagnostic work-up of patients with iron deficiency anaemia not responding to the routine therapy.

When children especially in older age group are found to be iron deficient, H. Pylori infection and other gastrointestinal pathologies especially celiac disease should be ruled out before giving iron therapy. As we have seen 
Table 2: Upper gastrointestinal (UGI) endoscopy finding

\begin{tabular}{|c|c|c|c|c|}
\hline \multirow{2}{*}{\multicolumn{2}{|c|}{ UGI endoscopy finding }} & \multicolumn{2}{|c|}{ Sex } & \multirow{2}{*}{$\begin{array}{c}\text { Total } \\
(\mathrm{n}=95)\end{array}$} \\
\hline & & $\operatorname{Male}(n=47)$ & Female $(n=48)$ & \\
\hline Normal & & $20(42.5 \%)$ & $15(31.2 \%)$ & $35(36.8 \%)$ \\
\hline Esophageal hype & & $3(6.3 \%)$ & $1(2.0 \%)$ & $4(4.2 \%)$ \\
\hline Gastro esophage & & $9(19.1 \%)$ & $7(14.5 \%)$ & $16(16.8 \%)$ \\
\hline \multirow{4}{*}{ Villous atrophy } & $\bullet$ Mild & $4(8.5 \%)$ & $4(8.3 \%)$ & $8(8.4 \%)$ \\
\hline & - Moderate & $5(10.6 \%)$ & $4(8.3 \%)$ & $9(9.4 \%)$ \\
\hline & - Severe & $9(19.1 \%)$ & $7(14.5 \%)$ & $16(16.8 \%)$ \\
\hline & - Total & $18(38.2 \%)$ & $15(31.2 \%)$ & $33(34.7 \%)$ \\
\hline Mucosal erosion & & $4(8.5 \%)$ & $3(6.2 \%)$ & $7(7.36 \%)$ \\
\hline
\end{tabular}

Table 3: Histopathology of duodenal biopsy in study population

\begin{tabular}{|c|c|c|c|c|}
\hline \multirow{2}{*}{\multicolumn{2}{|c|}{ Biopsy Finding }} & \multicolumn{2}{|c|}{ Sex } & \multirow[b]{2}{*}{ Total $(n=95)$} \\
\hline & & $\begin{array}{c}\text { Female } \\
(n=48)\end{array}$ & $\begin{array}{c}\text { Male } \\
(n=47)\end{array}$ & \\
\hline Normal & & $23(47.9 \%)$ & $17(36.1 \%)$ & $40(42.1 \%)$ \\
\hline \multicolumn{2}{|c|}{ H.Pyloriduodenitis } & $3(6.2 \%)$ & $6(12.7 \%)$ & $9(9.5 \%)$ \\
\hline \multirow{5}{*}{ Celiac } & - Marsh stage 1 & $6(1.2 \%)$ & $3(6.3 \%)$ & $9(9.5 \%)$ \\
\hline & - Marsh stage 2 & $4(8.3 \%)$ & $8(17.0 \%)$ & $12(12.6 \%)$ \\
\hline & - Marsh stage 3 & $5(10.4 \%)$ & $6(12.7 \%)$ & $11(11.6 \%)$ \\
\hline & - Marsh stage 3C & $0(0.0 \%)$ & $3(6.3 \%)$ & $3(3.2 \%)$ \\
\hline & - Total & $15(31.2 \%)$ & $20(42.5 \%)$ & $35(36.84 \%)$ \\
\hline \multicolumn{2}{|c|}{ Nonspecific duodenitis } & $7(14.5 \%)$ & $4(8.5 \%)$ & $11(11.6 \%)$ \\
\hline
\end{tabular}

Table 4: Correlation of serum tissuetransglutaminase (ttg) iga levels with endoscopic findings

\begin{tabular}{|c|c|c|c|c|}
\hline \multirow{2}{*}{\multicolumn{2}{|c|}{ UGI endoscopy finding }} & \multicolumn{2}{|c|}{ TTG (IU/MI) } & \multirow{2}{*}{$\operatorname{Total}(n=27)$} \\
\hline & & Negative & Positive & \\
\hline \multirow[t]{2}{*}{ Normal } & & $3(60 \%)$ & $2(40 \%)$ & $5(18.51 \%)$ \\
\hline & • Mild & $0(0 \%)$ & $6(100 \%)$ & $6((22.22 \%)$ \\
\hline \multirow[t]{2}{*}{ Villous atrophy } & - Moderate & $0(0 \%)$ & $7(100 \%)$ & $7(25.92 \%)$ \\
\hline & - Severe & $0(0 \%)$ & $9(100 \%)$ & $9(33.33 \%)$ \\
\hline
\end{tabular}

Table 5: Comorbidities

\section{Final Diagnosis}

Iron deficiency anemia (IDA)

IDA with inflammatory bowel disease

IDA with post streptococcal glomerulonephritis

IDA with Celiac disease

IDA with diabetes mellitus

IDA with H.Pyloriduodenitis

IDA with Nonspecific duodenitis

IDA with Erosive duodenitis

IDA with Giardiasis

\begin{tabular}{cc} 
Total & Percentage \\
39 & $41.05 \%$ \\
1 & $1.05 \%$ \\
1 & $1.05 \%$ \\
22 & $23.16 \%$ \\
3 & $3.16 \%$ \\
8 & $8.42 \%$ \\
11 & $11.58 \%$ \\
7 & $7.37 \%$ \\
3 & $3.16 \%$ \\
\hline 95 & $100 \%$
\end{tabular}

from our study that maximum abnormal endoscopic and duodenal biopsy findings related to celiac disease. We can conclude that celiac disease, malabsorption and chronic blood loss due to giardiasis and $\mathrm{H}$. Pylori infection are the important gastrointestinal pathologies occurring in patients of iron deficiency anemia which can be confirmed by doing upper gastrointestinal endoscopic examination and duodenal biopsy. Hence upper gastrointestinal endoscopy has a definitive role in identifying the underlying cause of iron deficiency anemia in patients not responding to conventional therapy.

\section{Source of Funding}

None. 


\section{Conflict of Interest}

None.

\section{References}

1. The Johns Hopkins bloombergh school of public health and university Parul Christian international Nutrition; 2005.

2. Hershko C, Camaschella C. How I treat unexplained refractory Iron deficiency anemia; 2014. Available from: www.bloodjournal.org

3. Grisolano SW, Oxentenko AS, Murray JA, Burgart LJ, Dierkhising RA, Alexander JA. The Usefulness of Routine Small Bowel Biopsies in Evaluation of Iron Deficiency Anemia. J Clin Gastroenterol. 2004;38(9):756-60.

4. Dickey W, Kenny BD, McMillan SA, Porter KG, McConnell JB Gastric as well as Duodenal Biopsies May Be Useful in the Investigation of Iron Deficiency Anaemia. Scand J Gastroenterol. 1997;32(5):469-72.

5. Harewood GC, Holub JL, Lieberman DA. Variation in Small Bowel Biopsy Performance among Diverse Endoscopy Settings: Results from a National Endoscopic Database. American Journal of Gastroenterology. 2004;99(9):1790-1794. Available from: hitps://dx.doi.org/10.111//].1572-0241.2004.40176.x doi:10.1111/j.1572-0241.2004.40176.x
6. Kleigman RM, Jenson HB, Stanton. Iron deficiency anemia nelson textbook of pediatrics;. p. 2323.

7. Gulen H, Kasirga E, Yildirim SA, Kader S, Sahin G, Ayhan S. Diagnostic Yield of Upper Gastrointestinal Endoscopy in the Evaluation of Iron Deficiency Anemia in Older Children and Adolescents. Pediatr Hematol Oncol. 2011;28(8):694-701.

8. Gonen C, Yilmaz N, Yalcin M, Simsek I, Gonen O. Diagnostic yield of routine duodenal biopsies in iron deficiency anaemia: a study from Western Anatolia. Eur J Gastroenterol Hepato. 2007;19(1):37-41.

\section{Author biography}

Chandradeep Mastan Senior Resident

Rakesh Jora Professor

Priyanka Karnani Senior Resident

Cite this article: Mastan C, Jora R, Karnani P. Role of upper gastrointestinal endoscopy in children with iron deficiency anemia in western Rajasthan. IP Int J Med Paediatr Oncol 2020;6(2):48-51. 